Journal Of Mass Spectrometry

January 2015, Volume 50 Issue 1 Pages 175-181

http://dx.doi.org/10.1002/ims.3515

http://archimer.ifremer.fr/doc/00249/36067/

(c) 2015 John Wiley \& Sons, Ltd.

\title{
Identification and separation of saxitoxins using hydrophilic interaction liquid chromatography coupled to traveling wave ion mobility-mass spectrometry
}

\author{
Poyer Salome ${ }^{1,2}$, Loutelier-Bourhis Corinne ${ }^{1,2}$, Coadou Gael ${ }^{1,2}$, Mondeguer Florence ${ }^{3}$, \\ Enche Julien ${ }^{4}$, Bossee Anne ${ }^{4}$, Hess Philipp ${ }^{3}$, Afonso Carlos ${ }^{1,2,{ }^{*}}$
}

${ }^{1}$ Normandie Univ, COBRA, UMR 6014, F-76821 Mont St Aignan, France.

2 Univ Rouen, INSA Rouen, CNRS, IRCOF,FR 3038, F-76821 Mont St Aignan, France.

${ }^{3}$ IFREMER, Lab Phycotoxines, F-44311 Nantes 03, France.

${ }^{4}$ DGA Maitrise NRBC, Dept Anal Chim, F-91710 Vert Le Petit, France.

* Corresponding author : Carlos Afonso, email address : carlos.afonso@univ-rouen.fr

\begin{abstract}
:
The aim of this work was to develop a reliable and efficient analytical method to characterise and differentiate saxitoxin analogues (STX), including sulphated (gonyautoxins, GTX) and non-sulphated analogues. For this purpose, hydrophilic interaction liquid chromatography (HILIC) was used to separate sulphated analogues. We also resorted to ion mobility spectrometry to differentiate the STX analogues because this technique adds a new dimension of separation based on ion gas phase conformation. Positive and negative ionisation modes were used for gonyautoxins while positive ionisation mode was used for non-sulphated analogues. Subsequently, the coupling of these three complementary techniques, HILIC-IM-MS, permitted the separation and identification of STX analogues; isomer differentiation was achieved in HILIC dimension while non-sulphated analogues were separated in the IM-MS dimension. Additional structural characteristics concerning the conformation of STXs could be obtained using IM-MS measurements. Thus, the collision cross sections (CCS) of STXs are reported for the first time in the positive ionisation mode. These experimental CCSs correlated well with the calculated CCS values using the trajectory method.
\end{abstract}

Keywords : saxitoxin, ion mobility-mass spectrometry, isomers, multidimensional separation, HILIC 


\section{INTRODUCTION}

Saxitoxin (STX) and its analogues are very potent neurotoxins produced by marine dinoflagellates and cyanobacteria, and have been described as paralytic shellfish poisons (PSP). ${ }^{[1,2]}$ After initial isolation efforts by Onoue et al. ${ }^{[3]}$ ground-breaking work had been completed by Sommer et al. ${ }^{[4]}$ on the relationship between the appearance of dinoflagellates and the toxicity in shellfish. ${ }^{[5]}$ STX is referenced in Schedule 1 of the chemical weapons convention (CWC) because of its toxicity and the opportunity to produce it in large scale by either synthesis or micro-algal culture. ${ }^{[6,7]}$ The high toxicity of STX and its analogues towards humans is due to their ability to bind to voltage-gated sodium channels, which may result in partial or total paralysis of the respiratory tract and can therefore lead in the worst case to death of patients within short periods of time (e.g. $15 \mathrm{~min})$ following consumption of contaminated fish or shellfish. ${ }^{[8,9]}$ The unequivocal identification of STXs represents an issue to counteract bioterrorism and to promptly analyse marine samples for food security as STXs present in algae can be bio-accumulated by molluscs. ${ }^{[10]}$

STXs are highly polar compounds presenting numerous isomers. The toxicity of the different analogues can vary depending on the chemical functional groups they present. Different liquid chromatography-mass spectrometry (LC-MS) methods have been previously reported in the literature to detect, identify and differentiate these compounds. ${ }^{[11-15]}$ However, while some of these methodologies may be fast and sensitive, they require laborious sample preparation when samples represent complex matrices. ${ }^{[16]}$

Interestingly, the recent technique of ion mobility (IM) coupled to mass spectrometry (MS) allows ion separation in the gas phase, according to the size, shape and charge of the ions, has been coupled to MS and can be envisaged as a complementary approach to LC-MS methods. The drift time $\left(t_{D}\right)$ obtained by IM is related to the collision cross section $(\mathrm{CCS}, \Omega)$ which is 
representative of the three-dimensional structure of the ion. ${ }^{[17]}$ In the case of the travelling wave ion mobility (TWIM) cell, a relationship between $t_{D}$ and $\Omega$ has been determined according to:

$$
\Omega=A\left(t_{D}^{B}\right) \frac{z}{\sqrt{\mu}}
$$

Where $z$ is the ion charge, and $\mu=\mathrm{mM} /(\mathrm{m}+\mathrm{M})$ is the reduced mass for the ion $(\mathrm{m})$ and the buffer gas molecules $(\mathrm{M})$. Using this relation, a calibration curve $\left(y=A x^{B}\right)$ can be plotted using compounds with known $\Omega .{ }^{[18,19]}$ IM-MS also proved to be a reliable and reproducible technique for the separation of isomers. ${ }^{[20-23]}$ It can be coupled to LC-MS affording another dimension of separation to the analysis. Indeed, LC-IM-MS can be carried out as the time scale of IM (ms) fits perfectly between that of the LC (minute) and time-of-flight-MS ( $\mu$ s) techniques. $^{[24]}$

Thus, considering all the potentialities of LC, IM and MS, we envisaged the coupling of these techniques to develop an efficient method for the identification and differentiation of STXs. Initially, direct introduction IM-MS experiments using electrospray ionisation (ESI) as well as HILIC-IM-MS were evaluated to differentiate STXs. Subsequently, according to Equation (1), we compared the different STX conformations. Finally, the theoretical and experimental determinations of the CCS values are here reported for the first time.

\section{EXPERIMENTAL}

\section{Chemicals and standard solutions}

Certified standards of STXs (STX, dcSTX, NEO, dcNEO, GTX1/4, dcGTX2/3, GTX5 and GTX2/3) were purchased from NRC-Canada. Fresh solutions were used as hydrolysis may occur in solution. HPLC-grade acetonitrile was supplied by VWR (Fontenay-sous-Bois, France) and polyalanine, ammonium acetate, formic and acetic acid from Sigma-Aldrich 
(Saint Quentin-Fallavier, France). Deionised water (18.2 M $\Omega$ ) was obtained from a Milli-Q apparatus (Waters, Saint-Quentin-Yvelines, France).

\section{HILIC conditions}

HILIC-MS experiments were performed using an ultra-high performance liquid chromatograph (nano acquity, Waters, Manchester, UK) system equipped with binary pumps, degasser, thermostated autosampler and column heater maintained at respectively $5^{\circ} \mathrm{C}$ and $35^{\circ} \mathrm{C}$, coupled to a hybrid quadrupole - ion mobility - time-of-flight mass spectrometer (Synapt G2 HDMS, Waters, Manchester, UK) equipped with an electrospray source. The system was fitted with a TSK gel amide 80 column $(5 \mu \mathrm{m}, 1 \mathrm{~mm}$ x $250 \mathrm{~mm})$ manufactured by TOSOH Bioscience (San Francisco, CA, USA). Eluent A was $2 \mathrm{mM}$ ammonium acetate buffer ( $\mathrm{pH} 3.5$ ) and $\mathrm{B}$ was acetonitrile containing $0.01 \%$ of acetic acid. The elution gradient was as following: $0 \min (80 \% \mathrm{~B}), 30 \mathrm{~min}(40 \% \mathrm{~B}), 35 \mathrm{~min}(40 \% \mathrm{~B})$, and $36 \min (80 \% \mathrm{~B})$. An equilibration time of 4 min was required to return the column to its initial conditions for a total run time of $40 \mathrm{~min}$. A flow rate of $50 \mu \mathrm{L} \mathrm{min}{ }^{-1}$ and sample volume injection of $1 \mu \mathrm{L}$ was used. The toxins sample were diluted at $3 \mathrm{mg} \mathrm{L}^{-1}$ in $\mathrm{H}_{2} \mathrm{O}$ containing $0.1 \%$ of acetic acid. Masslynx v4.1 and Driftscope v2.2 software were used to process data (Waters, Manchester, UK).

\section{IM-MS conditions}

Ion mobility-mass spectrometry experiments were carried out using the travelling wave ion mobility cell of the Synapt G2 HDMS instrument. Details of the instrument have been published elsewhere. ${ }^{[25]}$ The ESI source was operated in the positive ionisation mode for the determination of the experimental CCS values. The negative ionisation mode was also used for the detection of GTX derivatives. The experiments were performed with a source 
temperature of $90^{\circ} \mathrm{C}$ and desolvation gas temperature of $250^{\circ} \mathrm{C}$. Voltage parameters respectively for positive/negative ionisation were the following: capillary $3.0 / 2.1 \mathrm{kV}$, sampling cone 30/40 V, extraction cone 5.0/5.0 V.

For IM-MS experiments, data were acquired using 300 and $450 \mu$ s of mobility delay after trap release, respectively for positive and negative ionisation mode. The Helium cell gas flow and $\mathrm{N}_{2}$ IM gas flow were set to 180 and $90 \mathrm{~mL} \mathrm{~min}^{-1}$, respectively. Wave height was set at 40 $\mathrm{V}$ and wave velocity between 700 to $900 \mathrm{~m} \mathrm{~s}^{-1}$ depending on the coupling and ionisation mode. Optimisation of IM separation presented in Table S2 to S5 (supplementary information) used different parameters of the TWIM cell: $\mathrm{N}_{2}$ gas flow was set between 60 to $90 \mathrm{~mL} \cdot \mathrm{min}^{-1}$, wave velocity between 400 to $1600 \mathrm{~m} \mathrm{~s}^{-1}$ and wave height between 30 to $40 \mathrm{~V}$. Experiments were accomplished in the ' $\mathrm{V}$ ' resolution mode (resolution 20,000 FWHM) in the 50 to $600 \mathrm{~m} / \mathrm{z}$ range (analysis in the range of 50 to $1,200 \mathrm{~m} / \mathrm{z}$ was initially studied in order to improve the separation due to a larger $t_{D}$ scale, however, peaks were too large to obtain a good separation).

Experimental CCS values were estimated with the calibration method described in the literature using protonated polyalanine molecules in $\mathrm{N}_{2}$ and $\mathrm{He}$ as references to correct the non-uniform electric field of the TWIM cell (Figure S1 and S2, supplementary information). ${ }^{[19,26]}$ The instrumental IM conditions used for the calibration with polyalanine were the same as those used for STX analyses in the positive ionisation mode. All the drift time peaks were fitted with a Gauss function using the peak fitting tool of Origin 8.5 software (OriginLab).

\section{Theoretical calculations}

Structures of STXs were generated and geometry optimised by minimising their energy using the DISCOVER simulation package (Biosym Technologies, San Diego, CA, USA) and the 
consistent-valence force field (CVFF). Simulated annealing was performed at a set temperature (5000 iterations to $1000 \mathrm{~K}$ ). After the dynamics and slowly-quenched simulated annealing (slowly cooled for 5000 iterations to $300 \mathrm{~K}$ ), the structures were minimized with different steps of steepest descent and conjugated gradient method. This procedure was repeated several times to generate a large group of conformations which represent the possible energy minima. For each STX analogue, 50 structures with the lowest energies were retained. Theoretical CCS values have been obtained using the trajectory method (TM), the projection approximation (PA) and exact hard sphere scattering (EHSS) methods of MOBCAL ${ }^{[27,28]}$ on each singly-charged optimised structure. Gas polarisability and LennardJones $\left(\varepsilon_{\mathrm{o}}\right.$ and $\mathrm{r}_{\mathrm{o}}$ ) parameters of MOBCAL used to obtain CCS values with both helium and nitrogen as buffer gas (Table S1, supplementary information) were those previously reported by Zakharova et al. ${ }^{[29]}$ Optimised atomic energy and Van der Waals distance parameters used for $\mathrm{H}, \mathrm{N}, \mathrm{C}$, and $\mathrm{N}$ atoms in $\mathrm{N}_{2}$ and He used were reported by Campuzano et al. ${ }^{[21]}$

\section{RESULTS AND DISCUSSION}

\section{Saxitoxin analogues}

With ESI, positive ionisation mode proved to be more advantageous for the analysis of STX, NEO, dcSTX and dcNEO, probably due to the presence of the amine group. The resulting ESI mass spectra showed the corresponding protonated molecules as previously shown by Dell'Aversano et al. (data not shown). ${ }^{[14]}$ No significant in-source fragmentation was observed for these analogues, except loss of $\mathrm{H}_{2} \mathrm{O}$. In the case of GTX derivatives, both positive and negative ionisation modes were performed as these analogues possess both sulphate and amine functionalities. It is important to note that commercial solutions of isomers are only available as pairs and do not present the same concentration for each toxin; 
for example, the calibrant of GTX2/3 contains $114 \mu \mathrm{mol} \mathrm{L}^{-1}$ of GTX2 and $43 \mu \mathrm{mol} \mathrm{L}{ }^{-1}$ of GTX3. Some authors have associated the loss of $\mathrm{SO}_{3}$ to the instability of $[\mathrm{GTX} 2+\mathrm{H}]^{+}$and stability of $\left[\mathrm{GTX} 2-\mathrm{SO}_{3}+\mathrm{H}\right]^{+} ;^{[30,31]}$ this observation is confirmed by HILIC experiments described later in this paper.

To improve the detection and limit the fragmentation of the protonated molecules, the source and instrument parameters were optimised. However, even after this optimisation, intact GTX ions still remained more intense in the negative ionisation mode due to the fragmentation extent of GTX1, $-2,-5$ and dcGTX2 in the positive ionisation mode as already described. ${ }^{[11]}$ For instance, Table 2 shows relative abundances of the ions obtained from commercial GTX2/3 mixture in ESI spectra for both ionisation modes. Both $[\mathrm{M}+\mathrm{H}]^{+}$and $[\mathrm{M}-\mathrm{H}]^{-}$were observed with three different fragments, depending on the ionisation mode. In the negative ion ESI mass spectrum the intact $[\mathrm{GTX} 2 / 3-\mathrm{H}]^{-}$ion was detected as the base peak whereas in the positive ionisation mode the $[\mathrm{GTX} 2 / 3+\mathrm{H}]^{+}$form was detected only with a relative abundance of $14 \%$ due to extensive in-source fragmentation. It should be pointed out that the fragmentation of the deprotonated GTX2/3 (m/z 394.08) yielded a product ion at $\mathrm{m} / \mathrm{z} 351.07$ that corresponds to $[\mathrm{dcGTX} 2 / 3-\mathrm{H}]^{-}$. In addition, the protonated species at $\mathrm{m} / z 396.09$ yielded an intense product ion at $\mathrm{m} / \mathrm{z} 316.14$ which is a regioisomer of NEO. Consequently, the MS analysis appears more challenging than expected since fragmentation of some $[\mathrm{M}+\mathrm{H}]^{+}$, in particular from GTXs, produce fragment ions which are isomers of non-sulphated STX analogues.

Due to the low gas phase stability of $[\mathrm{GTX} 1 / 4+\mathrm{H}]^{+},[\mathrm{GTX} 2 / 3+\mathrm{H}]^{+},[\mathrm{GTX} 5+\mathrm{H}]^{+}$and $[\mathrm{dcGTX} 2 / 3+\mathrm{H}]^{+}$, the negative ionisation mode has been preferred for GTXs.

Then, ESI-MS/MS experiments were carried out without activation after the quadrupole selection to evaluate the stability of the precursor ion, excluding fragmentations which occur in source; for example, MS/MS spectra of protonated and deprotonated GTX2/3 isomers are 
presented in Figure 1. The fragment ions of $[\mathrm{GTX} 2 / 3-\mathrm{H}]^{-}$in Table 2 were produced most likely in the orifice skimmer region as the MS/MS spectrum on Figure 1a does not show fragment ions. On the contrary, the MS/MS spectrum of $[\mathrm{GTX} 2 / 3+\mathrm{H}]^{+}$showed extensive fragmentation without explicitly applying collision energy. The same features were observed for all GTX isomers.

Consequently, $[\mathrm{GTX}-\mathrm{H}]^{-}$ions have a significantly higher gas phase stability than the $[\mathrm{GTX}+\mathrm{H}]^{+}$ions. The major fragmentation in the positive ionisation mode consists in the neutral loss of $\mathrm{SO}_{3}$ yielding abundant $\left[\mathrm{GTX}+\mathrm{H}-\mathrm{SO}_{3}\right]^{+}$product ion. Indeed, GTX1, $-2,-5$ and dcGTX2 yielded abundant $\left[\mathrm{GTX}+\mathrm{H}-\mathrm{SO}_{3}\right]^{+}$ions whereas GTX3, -4 and dcGTX3 yielded principally intact $[\mathrm{GTX}+\mathrm{H}]^{+}$ions (relative abundance $90 \%$ ). These results were consistent with previous data. ${ }^{[14]}$ Fragment ions were observed in high percentages (85\% RA) for GTX1, -2 and dcGTX2, even when very soft desolvation conditions were used (i.e. low cone voltage). Both $[\mathrm{GTX}+\mathrm{H}]^{+}$and $\left[\mathrm{GTX}+\mathrm{H}-\mathrm{SO}_{3}\right]^{+}$ions also fragment with neutral loss of $\mathrm{H}_{2} \mathrm{O}$ as presented in Figure 1. Dissociation occurs in the ion source and during the transport of the ions through the different ion optics of the instrument.

From ESI-MS experiments, one of the main difficulties of STX analysis is the presence of numerous analogues, which can present diastereomers which could not be differentiated by MS. Moreover, in the case of the positive ionisation mode, another difficulty is encountered when the $\left[\mathrm{M}+\mathrm{H}-\mathrm{SO}_{3}\right]^{+}$fragment ions of some analogues exhibit the same $m / z$ values than protonated molecules of other analogues, as previously mentioned; indeed, [GTX2 $\left.+\mathrm{H}-\mathrm{SO}_{3}\right]^{+}$, $\left[\mathrm{GTX} 5+\mathrm{H}-\mathrm{SO}_{3}\right]^{+}$and $\left[\mathrm{dcGTX} 2+\mathrm{H}-\mathrm{SO}_{3}\right]^{+}$are respectively regioisomers of $[\mathrm{NEO}+\mathrm{H}]^{+}$, $[\mathrm{STX}+\mathrm{H}]^{+}$and $[\mathrm{dcNEO}+\mathrm{H}]^{+}$. Consequently, an upstream separation to MS appeared necessary to separate STX analogues.

\section{IM-MS results}


IM-MS coupling was first investigated to evaluate the capabilities of this technique for STX isomers differentiation in a rapid approach using direct sample infusion. Solutions of commercial toxin calibrants were diluted to $1 \mathrm{mg} \mathrm{L}^{-1}$ in $\mathrm{H}_{2} \mathrm{O} / \mathrm{MeCN}$ (50:50), infused and analysed as either mixtures or individually. Standards of STX, dcSTX, NEO, dcNEO and GTX5 could be infused individually while diastereomer mixtures of GTX1/4, GTX2/3 and dcGTX2/3 were infused without further separation. After optimisation of the different TWIM cell parameters (Table $\mathrm{S} 2$ to $\mathrm{S} 5$, supplementary information), the drift times $t_{D}$ were measured and the CCS could be determined (Table 3).

The separation of STXs by IM-MS was first investigated in the positive ionisation mode to obtain CCS values since the calibration of the TWIM cell is readily done thanks to the existence of numerous reference compounds in this mode. As described from Equation (1), CCS values can be determined from the experimental $t_{D}$. The calibration allows a comparison of CCS values which are independent of the experimental parameters and provide structural information.

The drift times of the toxins presented in Table 3 show a significant separation of STXs, depending on their functionalities. STX, NEO and their decarbamoyl derivatives present a more strongly folded conformation than the sulphate derivatives, which indicates that the sulphate group presents a higher influence than the carbamoyl group towards the threedimensional structure of STXs. Unfortunately, no diastereomer separation could be achieved through IM-MS for any of the mixtures of isomer pairs. As previously mentioned, loss of $\mathrm{SO}_{3}$ is the main dissociation pathway observed in the positive ionisation mode; thus, the CCS of the $\left[\mathrm{M}+\mathrm{H}-\mathrm{SO}_{3}\right]^{+}$product ions are also reported in Table 3. The average CCS values were calculated using different wave height, wave velocity and IM $\left(\mathrm{N}_{2}\right)$ gas flow parameters in the 50 to $600 \mathrm{~m} / \mathrm{z}$ range. Calibration curves were obtained for each case allowing for the 
calculation of CCS values. These CCs values were reproducible $(<1 \%$ variability) independently of the parameters used (Table S6, supporting information).

Interestingly, the $\mathrm{CCS}$ values of the $\left[\mathrm{GTX} 2 / 3+\mathrm{H}-\mathrm{SO}_{3}\right]^{+}(\mathrm{m} / \mathrm{z} \quad 316.14)$ and $\left[\mathrm{dcGTX} 2 / 3+\mathrm{H}-\mathrm{SO}_{3}\right]^{+}(\mathrm{m} / z$ 273.13) product ions resulting from the dissociation of GTX2/3 and dcGTX2/3, respectively, were significantly different from those of the protonated molecules of NEO $(\mathrm{m} / \mathrm{z}, 316.14)$ and dcNEO $(\mathrm{m} / \mathrm{z}$ 273.13) which correspond to their respective regioisomer. IM-MS measurement showed that $[\mathrm{NEO}+\mathrm{H}]^{+}\left(\mathrm{CCSexp}=99.2 \AA^{2}\right)$ was more compact than $\left[\mathrm{GTX} 2 / 3+\mathrm{H}-\mathrm{SO}_{3}\right]^{+}\left(\mathrm{CCSexp}=102.1 \AA^{2}\right)$ and that $m / z 273$ ions of $[\mathrm{dcNEO}+\mathrm{H}]^{+}\left(\mathrm{CCSexp}=91.8 \AA^{2}\right)$ was also more compact than $\left[\mathrm{dcGTX} 2 / 3+\mathrm{H}-\mathrm{SO}_{3}\right]^{+}$ $\left(C C S e x p=94.2 \AA^{2}\right)$. The main difference between these isomers is the hydroxyl group present at a different position of the analogue structures. Indeed, this hydroxyl group is positioned on the $\mathrm{N}_{1}$ atom for NEO and dcNEO while it is located on the $\mathrm{C}_{11}$ atom for $\left[\mathrm{GTX} 2 / 3+\mathrm{H}-\mathrm{SO}_{3}\right]^{+}$and $\left[\mathrm{dcGTX} 2 / 3+\mathrm{H}-\mathrm{SO}_{3}\right]^{+}$. These differences show the importance of the hydroxyl group position in the toxin structures. We could conclude that the hydroxyl group on the $\mathrm{N}_{1}$ position did not influence the CCS due to steric hindrance of the carbamoyl group, whereas the hydroxyl group on the $\mathrm{C}_{11}$ position had a significant influence and yielded higher CCS values.

Gonyautoxin analogues were also analysed in the negative ionisation mode. Resulting $t_{D}$ values are reported in Table 3. Unfortunately, no reference compound with known CCS was available in this $\mathrm{m} / \mathrm{z}$ and CCS range in the negative ionisation mode for singly-charged ions so the experimental CCS values were not determined for this ionisation mode. A differentiation of every toxin was observed, but complete separation of isomers was not achieved. Interestingly, a $t_{D}$ order inversion occurred for the two pairs GTX1/4 and GTX2/3 depending on the ionisation mode. In fact, a comparison of $t_{D}$ showed that GTX1/4 had a more folded conformation than GTX2/3 in the negative mode, whereas the contrary was 
observed for the positive ionisation mode. No relationship could be established between gonyautoxin gas phase conformations and the $t_{D}$ order inversion without an upstream chromatographic separation of the isomers pairs.

IM-MS coupling allows the fast separation of non-sulphated STXs analogues but not the differentiation of GTX isomers. The separation of diastereomer pairs is essential due to their different toxicity depending on the sulphate group orientation. In order to separate diastereoisomers and to circumvent any epimerisation phenomenon, the coupling of HILIC to IM-MS was then investigated.

\section{HILIC-IM-MS results}

The HILIC technique was chosen for the separation of STX analogues due to the high polarity of these compounds. Figure 2 represents the HILIC-IM-MS data of STXs in positive (a) and negative (b) ionisation modes. The three-dimensional data obtained from this coupling are processed in two steps; the extracted ion chromatogram (HILIC dimension) of a definite $\mathrm{m} / \mathrm{z}$ value allowed for the isolation of the ion mobility spectra of the corresponding retention time. Subsequently, the $m / z$ value was extracted from the ion mobility spectra to obtain the $t_{D}$ of the ion of interest (IM dimension).

Every diastereomer pair was separated in the HILIC dimension, but non-sulphated analogues were not chromatographically differentiated in these conditions. However, these nonsulphated analogues could be differentiated in the ion mobility spectrometry dimension (Figure 2a). All isomer analogues were slightly differentiated by IM-MS after HILIC separation in both ionisation modes. It is interesting to note that $[\mathrm{GTX}+\mathrm{H}]^{+}$isomers presented a better differentiation in the ion mobility dimension than $[\mathrm{GTX}-\mathrm{H}]^{-}$species. The order of drift times differed according to the ionisation mode; $[\mathrm{GTX} 1+\mathrm{H}]^{+}$and $[\mathrm{GTX} 2+\mathrm{H}]^{+}>$ $[\mathrm{GTX} 4+\mathrm{H}]^{+}$and $[\mathrm{GTX} 3+\mathrm{H}]^{+}$compared to $[\mathrm{GTX} 1-\mathrm{H}]^{-}$and $[\mathrm{GTX} 2-\mathrm{H}]^{-}<[\mathrm{GTX} 3-\mathrm{H}]^{-}$and 
$[\mathrm{GTX} 4-\mathrm{H}]^{-}$. This inversion could be explained by the charge repulsion between the two quaternary ammonium cations in the presence of the sulphate group behind the molecular plane for GTX1 and GTX2 in the positive ionisation mode. This hypothesis could also explain the fragmentation and the instability due to the charge repulsion of protonated GTX1 and GTX2.

No inversion in the drift time order was observed depending on the ionisation mode for dcGTX2 and dcGTX3, CCS $_{\mathrm{dcGTX} 3}>\mathrm{CCS}_{\mathrm{dcGTX} 2}$. It is also important to note that after the loss of the $\mathrm{SO}_{3}$ group on gonyautoxin chiral centres, the resulting isomer fragment ions from protonated GTX1/4, GTX2/3 and dcGTX2/3 presented identical drift times in the positive ionisation mode $\left(\mathrm{t}_{\mathrm{D}}\left[\mathrm{GTX} 1+\mathrm{H}-\mathrm{SO}_{3}\right]^{+}=\mathrm{t}_{\mathrm{D}}\left[\mathrm{GTX} 4+\mathrm{H}-\mathrm{SO}_{3}\right]^{+}=4.07 \mathrm{~ms}, \mathrm{t}_{\mathrm{D}}\left[\mathrm{GTX} 2+\mathrm{H}-\mathrm{SO}_{3}\right]^{+}=\right.$ $\mathrm{t}_{\mathrm{D}}\left[\mathrm{GTX} 3+\mathrm{H}-\mathrm{SO}_{3}\right]^{+}=3.99 \mathrm{~ms}, \mathrm{t}_{\mathrm{D}}\left[\mathrm{dcGTX} 2+\mathrm{H}-\mathrm{SO}_{3}\right]^{+}=\mathrm{t}_{\mathrm{D}}\left[\mathrm{dcGTX} 3+\mathrm{H}-\mathrm{SO}_{3}\right]^{+}=3.56 \mathrm{~ms}$ for a wave velocity of $900 \mathrm{~m} \mathrm{~s}^{-1}$ ).

Thus, HILIC-IM-MS is a complementary coupling that allows for the differentiation of all the studied analogues; the separation of gonyautoxin isomers is achieved in the HILIC dimension while the differentiation of STX, dcSTX, NEO and dcNEO is obtained in the ion mobility dimension. Moreover, this coupling allows CCS determination on each individual species whereas IM-MS alone permitted the CCS determination of diastereomer pairs. This finding constitutes a major result for the characterisation of STX analogues.

In order to compare IM-MS results to STX structures, theoretical CCS values were calculated for fifty structures of STXs obtained by molecular dynamics. Optimised parameters of MOBCAL were used for both nitrogen and helium conditions. The different equations of correlation between experimental and theoretically calculated CCS values were obtained with $\mathrm{He}$ and $\mathrm{N}_{2}$ parameters. A good correlation was observed between the experimental and the calculated CCS values for the results obtained with the TM algorithm in $\mathrm{He}$ in the positive ionisation mode (Figure 3). This correlation emphasizes the importance of ion mobility 
dimension to characterise STXs, and confirms previous hypothesis on positive ion structures for $[\mathrm{NEO}+\mathrm{H}]^{+},[\mathrm{dcNEO}+\mathrm{H}]^{+},\left[\mathrm{GTX} 2 / 3+\mathrm{H}-\mathrm{SO}_{3}\right]^{+}$and $\left[\mathrm{dcGTX} 2 / 3+\mathrm{H}-\mathrm{SO}_{3}\right]^{+}$, but not the different configurations of GTXs between the positive and negative ionisation modes.

\section{CONCLUSION}

The differentiation of STXs using HILIC-IM-MS coupling to obtain a multi-dimensional separation analysis was examined. Gonyautoxins could be analysed in both positive and negative ionisation modes using ESI-MS, while non-sulphated analogues could only be detected in positive mode. The negative ionisation mode, which had been rarely reported in literature for STX analyses, was significantly more sensitive than the positive ionisation mode. In addition, $[\mathrm{GTX}-\mathrm{H}]^{-}$ions showed a better stability than the $[\mathrm{GTX}+\mathrm{H}]^{+}$species which underwent significant fragmentation.

HILIC-MS permitted the separation and identification of the GTX isomers whereas IM-MS dimension permitted the separation of the non-sulphated analogues. The coupling of the three techniques appeared necessary to achieve the separation of all species studied. Thus, HILIC and IM proved to be complementary for the separation of STXs derivatives. Moreover, the HILIC-IM-MS coupling allowed for the determination of experimental CCS values of STX derivatives, which were compared with the theoretical values obtained by molecular dynamic. Therefore, structural characterisation as well as quantification of these toxins could be envisaged. These studies are under investigation in the laboratory, and, in particular, we are focusing on the gas phase reactivity of the different toxin ion species to understand their gas phase behaviour.

\section{ACKNOWLEDGEMENTS}


The authors gratefully thank the Région Haute Normandie (CRUNCh network), the Direction

Générale de l'Armement (DGA), the European regional development fund (ERDF) N³1708, the Centre de ressources informatiques de Haute-Normandie (CRIHAN) and the Labex SynOrg (ANR-11-LABX-0029) for financial support. We also acknowledge Marie HubertRoux for technical support.

\section{REFERENCES}

[1] M. Wiese, P. M. D'Agostino, T. K. Mihali, M. C. Moffitt, B. A. Neilan. Neurotoxic alkaloids: Saxitoxin and its analogs. Mar Drugs 2010, 8, 2185.

[2] A. Negri, L. Llewellyn, J. Doyle, N. Webster, D. Frampton, S. Blackburn. Paralytic shellfish toxins are restricted to few species among australia's taxonomic diversity of cultured microalgae. J Phycol 2003, 39, 663.

[3] Y. Onoue, T. Noguchi, J. Maruyama, K. Hashimoto, H. Seto. Properties of two toxins newly isolated from oysters. J. Agric. Food Chem. 1931, 2, 420.

[4] H. Sommer, K. F. Meyer. Paralytic shellfish poisoning. Arch. Pathol. 1937, 24, 560.

[5] P. D. Baker, A. R. Humpage. Toxicity associated with commonly occurring cyanobacteria in surface waters of the murray-darling basin, australia. Mar. Freshwater Res. 1994, 45, 773.

[6] A. Stuken, R. J. Orr, R. Kellmann, S. A. Murray, B. A. Neilan, K. S. Jakobsen. Discovery of nuclear-encoded genes for the neurotoxin saxitoxin in dinoflagellates. PLoS One 2011, 6, e20096.

[7] A. P. Thottumkara, W. H. Parsons, J. Du Bois. Saxitoxin. Angew Chem Int Ed Engl 2014, 53, 5760.

[8] T. Narahashi, H. G. Haas, E. F. Therrien. Saxitoxin and tetrodotoxin: Comparison of nerve blocking mechanism. Science 1967, 157, 1441.

[9] K. D. Cusick, G. S. Sayler. An overview on the marine neurotoxin, saxitoxin: Genetics, molecular targets, methods of detection and ecological functions. Mar Drugs 2013, 11, 991.

[10] K. G. Sellner, G. J. Doucette, G. J. Kirkpatrick. Harmful algal blooms: Causes, impacts and detection. J Ind Microbiol Biotechnol 2003, 30, 383.

[11] C. Dell'Aversano, P. Hess, M. A. Quilliam. Hydrophilic interaction liquid chromatography--mass spectrometry for the analysis of paralytic shellfish poisoning (psp) toxins. J Chromatogr A 2005, 1081, 190.

[12] L. Zhuo, Y. Yin, W. Fu, B. Qiu, Z. Lin, Y. Yang, L. Zheng, J. Li, G. Chen. Determination of paralytic shellfish poisoning toxins by hilic-ms/ms coupled with dispersive solid phase extraction. Food Chem 2013, 137, 115. 
[13] M. Diener, K. Erler, B. Christian, B. Luckas. Application of a new zwitterionic hydrophilic interaction chromatography column for determination of paralytic shellfish poisoning toxins. J Sep Sci 2007, 30, 1821.

[14] C. Dell'Aversano, G. K. Eaglesham, M. A. Quilliam. Analysis of cyanobacterial toxins by hydrophilic interaction liquid chromatography-mass spectrometry. J Chromatogr A 2004, 1028, 155.

[15] X. Fang, X. Fan, Y. Tang, J. Chen, J. Lu. Liquid chromatography/quadrupole time-offlight mass spectrometry for determination of saxitoxin and decarbamoylsaxitoxin in shellfish. J Chromatogr A 2004, 1036, 233.

[16] M. Halme, M. L. Rapinoja, M. Karjalainen, P. Vanninen. Verification and quantification of saxitoxin from algal samples using fast and validated hydrophilic interaction liquid chromatography-tandem mass spectrometry method. J Chromatogr B Analyt Technol Biomed Life Sci 2012, 880, 50.

[17] C. Lapthorn, F. Pullen, B. Z. Chowdhry. Ion mobility spectrometry-mass spectrometry (ims-ms) of small molecules: Separating and assigning structures to ions. Mass Spectrom Rev 2013, 32, 43.

[18] Y. Zhong, S. J. Hyung, B. T. Ruotolo. Characterizing the resolution and accuracy of a second-generation traveling-wave ion mobility separator for biomolecular ions. Analyst 2011, 136, 3534.

[19] M. F. Bush, I. D. Campuzano, C. V. Robinson. Ion mobility mass spectrometry of peptide ions: Effects of drift gas and calibration strategies. Anal Chem 2012, 84, 7124.

[20] H. Li, K. Giles, B. Bendiak, K. Kaplan, W. F. Siems, H. H. Hill, Jr. Resolving structural isomers of monosaccharide methyl glycosides using drift tube and traveling wave ion mobility mass spectrometry. Anal Chem 2012, 84, 3231.

[21] I. Campuzano, M. F. Bush, C. V. Robinson, C. Beaumont, K. Richardson, H. Kim, H. I. Kim. Structural characterization of drug-like compounds by ion mobility mass spectrometry: Comparison of theoretical and experimentally derived nitrogen collision cross sections. Anal Chem 2012, 84, 1026.

[22] A. Revesz, D. Schroder, T. A. Rokob, M. Havlik, B. Dolensky. In-flight epimerization of a bis-troger base. Angew Chem Int Ed Engl 2011, 50, 2401.

[23] V. Domalain, V. Tognetti, M. Hubert-Roux, C. M. Lange, L. Joubert, J. Baudoux, J. Rouden, C. Afonso. Role of cationization and multimers formation for diastereomers differentiation by ion mobility-mass spectrometry. J Am Soc Mass Spectrom 2013, 24, 1437.

[24] Y. Yamaguchi, W. Nishima, S. Re, Y. Sugita. Confident identification of isomeric nglycan structures by combined ion mobility mass spectrometry and hydrophilic interaction liquid chromatography. Rapid Commun Mass Spectrom 2012, 26, 2877.

[25] K. Giles, J. P. Williams, I. Campuzano. Enhancements in travelling wave ion mobility resolution. Rapid Commun Mass Spectrom 2011, 25, 1559.

[26] D. P. Smith, T. W. Knapman, I. Campuzano, R. W. Malham, J. T. Berryman, S. E. Radford, A. E. Ashcroft. Deciphering drift time measurements from travelling wave ion mobility spectrometry-mass spectrometry studies. Eur J Mass Spectrom (Chichester, Eng) 2009, 15, 113.

[27] A. A. Shvartsburg, M. F. Jarrold. An exact hard-spheres scattering model for the mobilities of polyatomic ions. Chem. Phys. Lett. 1996, 261, 86. 
[28] M. F. Mesleh, J. M. Hunter, A. A. Shvartsburg, G. C. Schatz, M. F. Jarrold. Structural information from ion mobility measurements: Effects of the long-range potential. $J$ Phys Chem 1996, 100, 16082.

[29] N. L. Zakharova, C. L. Crawford, B. C. Hauck, J. K. Quinton, W. F. Seims, H. H. Hill, Jr., A. E. Clark. An assessment of computational methods for obtaining structural information of moderately flexible biomolecules from ion mobility spectrometry. $J$ Am Soc Mass Spectrom 2012, 23, 792.

[30] F. A. Dorr, B. Kovacevi, Z. B. Maksi, E. Pinto, D. A. Volmer. Intriguing differences in the gas-phase dissociation behavior of protonated and deprotonated gonyautoxin epimers. J Am Soc Mass Spectrom 2011, 22, 2011.

[31] S. Pleasance, S. W. Ayer, M. V. Laycock, P. Thibault. Ionspray mass spectrometry of marine toxins. lii. Analysis of paralytic shellfish poisoning toxins by flow-injection analysis, liquid chromatography/mass spectrometry and capillary electrophoresis/mass spectrometry. Rapid Commun Mass Spectrom 1992, 6, 14. 
Table 1. Structures of the principal saxitoxin analogues.

\begin{tabular}{|c|c|c|c|c|c|c|}
\hline \multirow{5}{*}{ 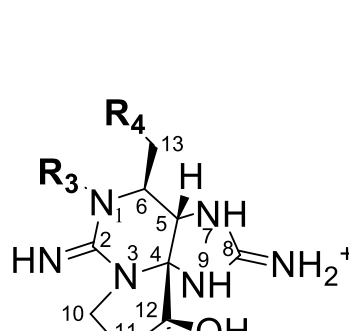 } & R1 & $\mathbf{R 2}$ & $\mathbf{R 3}$ & Carbamoyl & Decarbamoyl & N-sulfocarbamoyl \\
\hline & $\mathrm{H}$ & $\mathrm{H}$ & $\mathrm{H}$ & STX & dcSTX & GTX5 \\
\hline & $\mathrm{H}$ & $\mathrm{H}$ & $\mathrm{OH}$ & NEO & dcNEO & GTX6 \\
\hline & $\mathrm{OSO}_{3}^{-}$ & $\mathrm{H}$ & $\mathrm{H}$ & GTX2 & dcGTX2 & $\mathrm{C} 1$ \\
\hline & $\mathrm{H}$ & $\mathrm{OSO}_{3}^{-}$ & $\mathrm{H}$ & GTX3 & dcGTX3 & $\mathrm{C} 2$ \\
\hline \multirow{3}{*}{$\mathbf{R}_{\mathbf{1}}^{\prime \prime \prime \mathbf{R}_{\mathbf{2}}}$} & $\mathrm{OSO}_{3}^{-}$ & $\mathrm{H}$ & $\mathrm{OH}$ & GTX1 & dcGTX1 & $\mathrm{C} 3$ \\
\hline & $\mathrm{H}$ & $\mathrm{OSO}_{3}^{-}$ & $\mathrm{OH}$ & GTX4 & dcGTX4 & $\mathrm{C} 4$ \\
\hline & & $\mathbf{R 4}$ & & $\mathrm{H}_{2} \mathrm{~N}-\mathrm{COO}-$ & HO- & ${ }^{-} \mathrm{O}_{3} \mathrm{~S}-\mathrm{NH}-\mathrm{COO}-$ \\
\hline
\end{tabular}

Table 2. Relative abundance of the ions present in the ESI mass spectra of GTX2/3, in the positive and negative ionisation mode, respectively. Cone voltage of $30 \mathrm{~V}$ was applied for positive and $40 \mathrm{~V}$ for negative ionisation mode.

\begin{tabular}{ccc|ccc}
\hline Positive ions & $m / z$ & $\%$ & Negative ions & $m / z$ & $\%$ \\
\hline$[\mathrm{M}+\mathrm{H}]^{+}$ & 396.09 & 14 & {$[\mathbf{M}-\mathbf{H}]^{-}$} & $\mathbf{3 9 4 . 0 8}$ & $\mathbf{1 0 0}$ \\
{$\left[\mathrm{M}+\mathrm{H}-\mathrm{H}_{2} \mathrm{O}\right]^{+}$} & 378.08 & 6 & {$\left[\mathrm{M}-\mathrm{H}-\mathrm{H}_{2} \mathrm{O}\right]^{-}$} & 376.07 & 24 \\
{$\left[\mathbf{M}+\mathbf{H}-\mathbf{S O}_{3}\right]^{+}$} & $\mathbf{3 1 6 . 1 4}$ & $\mathbf{1 0 0}$ & {$\left[\mathrm{M}-\mathrm{H}-\mathrm{CONH}_{2}\right]^{-}$} & 351.07 & 7 \\
{$\left[\mathrm{M}+\mathrm{H}-\mathrm{SO}_{3}-\mathrm{H}_{2} \mathrm{O}\right]^{+}$} & 298.13 & 6 & {$\left[\mathrm{HSO}_{4}\right]^{-}$} & 96.96 & 10 \\
\hline
\end{tabular}


Table 3. Extracted $m / z$, drift time and CCS values in He with standard deviation.

\begin{tabular}{ccccc|cccc|cc}
\hline \multirow{2}{*}{ Toxin } & \multicolumn{5}{c|}{$[\mathrm{M}+\mathrm{H}]^{+}$} & \multicolumn{3}{c|}{$\left[\mathrm{M}+\mathrm{H}-\mathrm{SO}_{3}\right]^{+}$} & \multicolumn{3}{c}{$[\mathrm{M}-\mathrm{H}]^{-}$} \\
\cline { 2 - 11 } & $m / z$ & $\mathrm{t}_{\mathrm{D}}{ }^{\mathrm{a}}$ & $\mathrm{CCS}^{\mathrm{b}}$ & $\sigma_{\mathrm{CCS}}$ & $m / z$ & $\mathrm{t}_{\mathrm{D}}{ }^{\mathrm{a}}$ & $\mathrm{CCS}^{\mathrm{b}}$ & $\sigma_{\mathrm{CCS}}$ & $m / z$ & $\mathrm{t}_{\mathrm{D}}{ }^{\mathrm{a}}$ \\
\hline STX & 300.14 & 3.39 & 97.2 & 0.3 & - & - & - & - & - & - \\
dcSTX & 257.13 & 3.02 & 89.7 & 0.4 & - & - & - & - & - & - \\
NEO & 316.14 & 3.48 & 99.2 & 0.2 & - & - & - & - & - & - \\
dcNEO & 273.13 & 3.11 & 91.8 & 0.3 & - & - & - & - & - & - \\
GTX5 & 380.09 & 4.13 & 111.7 & 0.9 & 300.14 & 3.40 & 97.7 & 0.4 & 378.08 & 3.55 \\
GTX2/3 & 396.09 & 4.24 & 114.7 & 0.4 & 316.14 & 3.53 & 102.1 & 0.3 & 394.08 & 3.76 \\
dcGTX2/3 & 353.09 & 3.90 & 107.9 & 0.4 & 273.13 & 3.16 & 94.2 & 0.5 & 351.07 & 3.31 \\
GTX1/4 & 412.09 & 4.27 & 115.2 & 0.4 & 332.13 & 3.61 & 103.4 & 0.1 & 410.07 & 3.73 \\
\hline
\end{tabular}

${ }^{\mathrm{a}} \mathrm{t}_{\mathrm{D}}$ extracted from toxins individually analysed by IM-MS analysis obtained for a wave velocity of 800 and $700 \mathrm{~m} \mathrm{~s}^{-1}$ in positive and negative ionisation modes, respectively.

${ }^{\mathrm{b}}$ CCS average and standard deviation $\left(\sigma_{\mathrm{CCS}}\right)$ calculated for $\mathrm{n}=4$ different IM-MS velocity wave and $\mathrm{N}_{2}$ gas flow parameters in mixture and with toxins infused individually using calibration with the CCS values of polyalanine in He. 
Figure 1. ESI-MS/MS spectra of GTX2/3 isomer mixture in (a) negative and (b) positive ionisation mode without applying collision energy. the fragmentation of the $[\mathrm{GTX} 2 / 3+\mathrm{H}]+$ protonated species during ion transmission in the spectrometer is due to the instability of the [GTX2 + H]+analogue according to Pleasance et al.[31]

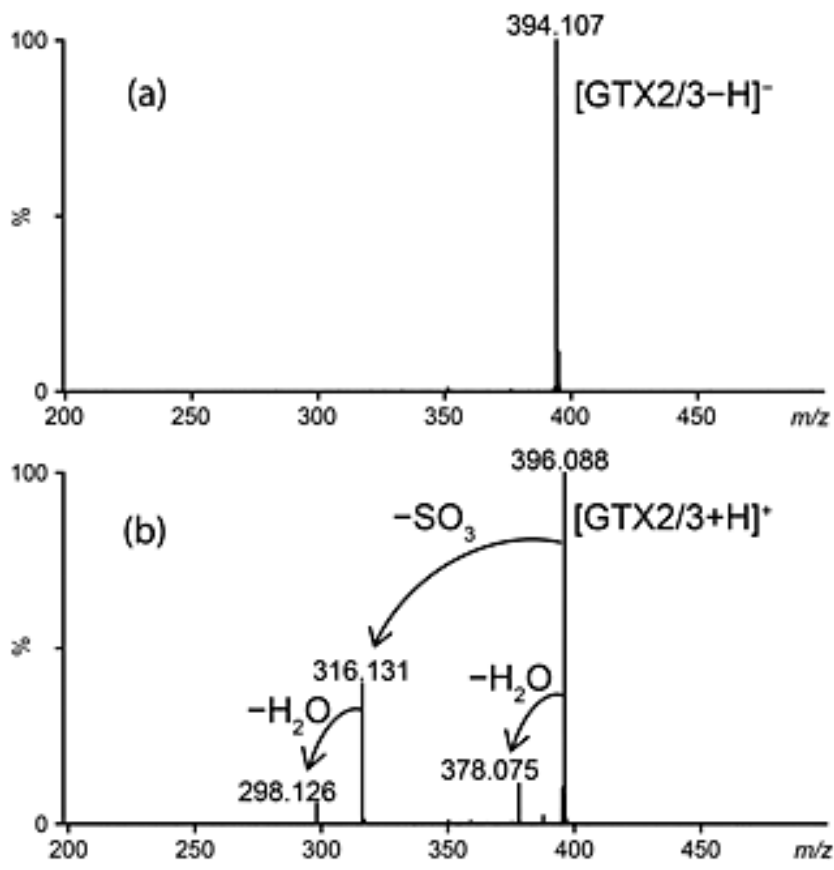


Figure 2. Extracted retention times and tD of the HILIC-IM-MS coupling for positive (a) and negative (b) ionisation modes. Wave velocities were fixed to 900 and $800 \mathrm{~m} \mathrm{~s}-1$ for positive and negative ionisation modes, respectively. Extracted retention times and $\mathrm{tD}$ of dcGTX2, GTX2 and GTX1 are represented in blue. Retention times corresponding to fragment ions of toxins are represented in red. Due to the fragmentation of $[\mathrm{M}+\mathrm{H}]+$ +ions of dcGTX2, GTX2 and GTX5, some interferences between the extracted ion chromatograms (EICs) of protonated dcGTX2, GTX2 and GTX5 and the EICs of [M+H-SO3]+ions corresponding to $\mathrm{m} / \mathrm{z}$ values of protonated STX, NEO and dcNEO could not be avoided. Due to the low intensity of $[\mathrm{M}+\mathrm{H}]+$ ions, EICs of dcGTX2, GTX2 and GTX1 represented are extracted from the $\mathrm{m} / \mathrm{z}$ values corresponding to $[\mathrm{M}+\mathrm{H}-\mathrm{SO} 3]+$ ions. All extracted ion mobility spectra are from $[\mathrm{M}+\mathrm{H}]+$ or $[\mathrm{M}-\mathrm{H}]-$ ions.

(a)

(b)

Figure 3. CCSexp $=f(C C S c a l c)$. Correlation between calculated and experimental CCS values obtained with MOBCAL in He optimised conditions. The theoretical CCS average values are calculated from values of polyalanine in He for calibration. Experimental and theoretically calculated CCS average values as well as correlation curves in N2 are presented in supplementary information.
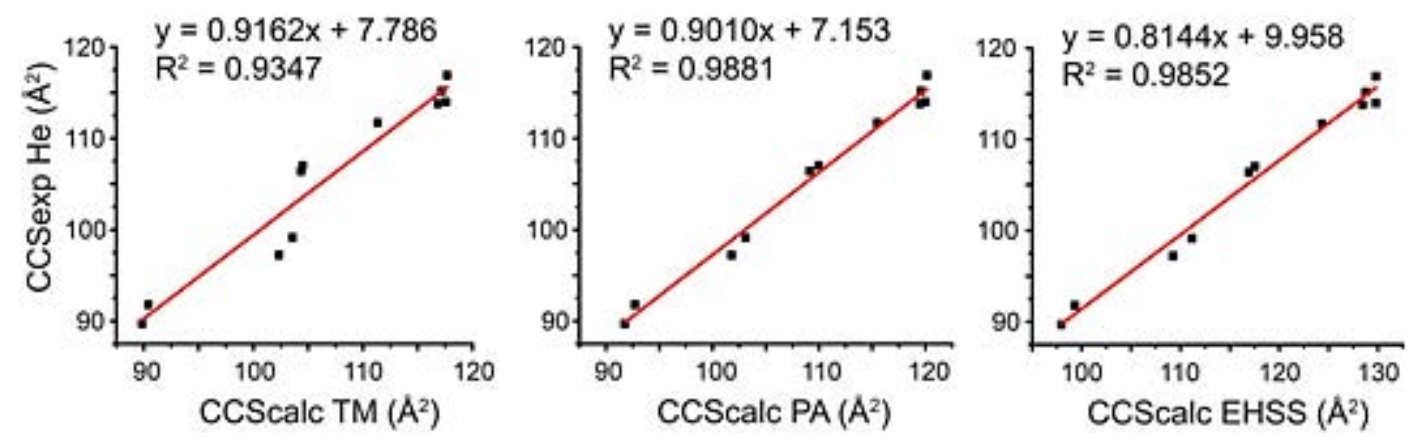
Identification and separation of saxitoxins using hydrophilic interaction liquid chromatography coupled to traveling wave ion mobility-mass spectrometry

Salomé Poyer, ${ }^{a}$ Corinne Loutelier-Bourhis, ${ }^{a}$ Gaël Coadou, ${ }^{a}$ Florence Mondeguer, ${ }^{b}$ Julien Enche, ${ }^{\mathrm{c}}$ Anne Bossée, ${ }^{\mathrm{c}}$ Philipp Hess, ${ }^{\mathrm{b}}$ Carlos Afonso ${ }^{\mathrm{a}^{*}}$

${ }^{a}$ Normandie Université, COBRA, UMR 6014 et FR 3038 ; Université de Rouen ; INSA de Rouen ; CNRS, IRCOF, 1 rue Tesnière, 76821 Mont-Saint-Aignan Cedex, France.

${ }^{\mathrm{b}}$ IFREMER, Laboratoire Phycotoxines, F-44311 Nantes 03, France.

${ }^{\mathrm{c}}$ DGA Maîtrise NRBC, département Analyse Chimique, F-91710 Vert-Le-Petit, France.

*Corresponding author carlos.afonso@univ-rouen.fr

\section{Supplementary material}




\section{CONTENTS}

Table S1. Polarisability, Mass and Lennard-Jones $\left(\varepsilon_{\mathrm{o}}\right.$ and $\mathrm{r}_{\mathrm{o}}$ ) parameters used in MOBCAL depending on the gas.

Table S2. Drift time difference between NEO and dcNEO

Table S3. Resolution peak to peak between NEO and dcNEO S5

Table S4. Drift time difference between GTX2/3 and dcGTX2/3 S6

Table S5. Resolution peak to peak between GTX2/3 and dcGTX2/3 S7

Table S6. CCS reproducibility of STX for different ion mobility conditions S8

Table S7. Experimental and theoretically calculated CCS averages in He S9

Table S8. Experimental and theoretically calculated CCS averages in $\mathrm{N}_{2}$ S9

Figure S1. TWIM slope calibration using $\mathrm{N}_{2}$ polyalanine values S10

Figure S2. TWIM slope calibration using He polyalanine values S10

Figure S3. Correlation between calculated and experimental CCS values obtained with MOBCAL in $\mathrm{N}_{2}$ optimised conditions. $\mathrm{S} 11$ 
Table S1. Polarisability, Mass and Lennard-Jones $\left(\varepsilon_{\mathrm{o}}\right.$ and $\left.\mathrm{r}_{\mathrm{o}}\right)$ parameters used in MOBCAL depending on the gas.

\begin{tabular}{ccccc}
\hline Gas & Polarisability $\left(\times 10^{-30} \mathrm{~m}^{3}\right)$ & Mass $(\mathrm{au})$ & $\varepsilon_{\mathrm{o}}\left(\mathrm{x} 10^{-3} \mathrm{eV}\right)$ & $\mathrm{r}_{\mathrm{o}}\left(\mathrm{x} 10^{-10} \mathrm{~m}\right)$ \\
\hline $\mathrm{He}$ & 0.204956 & 4.0026 & 1.34 & 3.043 \\
$\mathrm{~N}_{2}$ & 1.740 & 28.0134 & 7.915 & 3.919 \\
\hline
\end{tabular}


Table S2. Drift time difference between NEO and dcNEO for different ion mobility parameters in positive ionization mode. (a) wave height of $40 \mathrm{~V}$, (b) wave height of $30 \mathrm{~V}$. The green values correspond to the most important drift time difference and red values to the lowest differences. The bolt value corresponds to the highest drift time differences.

(a)

\begin{tabular}{|c|c|c|c|c|c|}
\hline \multirow{2}{*}{\multicolumn{2}{|c|}{$\Delta_{\text {NEO-dcNEO }}$}} & \multicolumn{4}{|c|}{ Gas flow $\left(\mathrm{mL} \min ^{-1}\right)$} \\
\hline & & 60 & \multirow{2}{*}{$\begin{array}{c}70 \\
0.20\end{array}$} & \multirow{2}{*}{$\begin{array}{c}80 \\
0.22\end{array}$} & \multirow{2}{*}{$\begin{array}{r}90 \\
0.24\end{array}$} \\
\hline \multirow{12}{*}{ 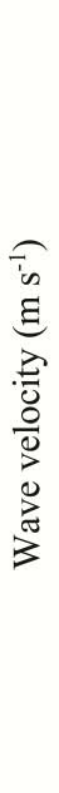 } & 500 & 0.16 & & & \\
\hline & 600 & 0.18 & 0.21 & 0.25 & 0.26 \\
\hline & 700 & 0.20 & 0.23 & 0.28 & 0.33 \\
\hline & 800 & 0.20 & 0.27 & 0.32 & 0.37 \\
\hline & 900 & 0.25 & 0.31 & 0.36 & 0.42 \\
\hline & 1000 & 0.28 & 0.34 & 0.40 & \\
\hline & 1100 & 0.30 & 0.38 & 0.45 & \\
\hline & 1200 & 0.33 & 0.41 & & \\
\hline & 1300 & 0.36 & 0.45 & & \\
\hline & 1400 & 0.40 & & & \\
\hline & 1500 & 0.42 & & & \\
\hline & 1600 & 0.45 & & & \\
\hline
\end{tabular}

(b)

\begin{tabular}{|c|c|c|c|c|c|}
\hline \multirow{2}{*}{\multicolumn{2}{|c|}{$\Delta_{\text {NEO-dcNEO }}$}} & \multicolumn{4}{|c|}{ Gas flow $\left(\mathrm{mL} \mathrm{min}^{-1}\right)$} \\
\hline & & 60 & 70 & 80 & 90 \\
\hline \multirow{7}{*}{ 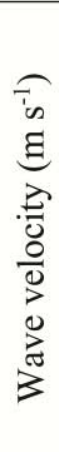 } & 400 & 0.22 & 0.26 & 0.29 & 0.33 \\
\hline & 500 & 0.24 & 0.30 & 0.32 & 0.40 \\
\hline & 600 & 0.27 & 0.35 & 0.41 & 0.48 \\
\hline & 700 & 0.32 & 0.40 & 0.48 & \\
\hline & 800 & 0.36 & 0.45 & & \\
\hline & 900 & 0.42 & & & \\
\hline & 1000 & 0.46 & & & \\
\hline
\end{tabular}

Ion mobility parameters were optimised to obtain the highest peak resolution as an alternative to the highest drift time difference.

$$
\Delta_{a-b}=t_{D_{a}}-t_{D_{b}}
$$

Where $\Delta$ is the drift time difference between the ion a and the ion $\mathrm{b}$.

$$
R_{a-b}=\frac{2\left(t_{D_{a}}-t_{D_{b}}\right)}{W b_{a}+W b_{b}}
$$

Where $\mathrm{R}$ is the resolution peak to peak and $\mathrm{Wb}$ is the Width at the base of the corresponding ion mobility peak. ${ }^{[1]}$ 
Table S3. Resolution peak to peak between NEO and dcNEO for different ion mobility parameters in positive ionization mode. (a) wave height of $40 \mathrm{~V}$, (b) wave height of $30 \mathrm{~V}$. The green values correspond to the most important drift time difference and red values to the lowest differences. The bolt value corresponds to the highest drift time differences.

\begin{tabular}{|c|c|c|c|c|c|}
\hline \multirow{2}{*}{\multicolumn{2}{|c|}{$\mathrm{R}_{\text {NEO-dcNEO }}$}} & \multicolumn{4}{|c|}{ Gas flow $\left(\mathrm{mL} \min ^{-1}\right)$} \\
\hline & & \multirow{2}{*}{$\begin{array}{c}60 \\
0.68\end{array}$} & \multirow{2}{*}{$\begin{array}{c}70 \\
0.86\end{array}$} & \multirow{2}{*}{$\begin{array}{c}80 \\
0.88\end{array}$} & \multirow{2}{*}{\begin{tabular}{|c|}
90 \\
0.98
\end{tabular}} \\
\hline \multirow{12}{*}{ 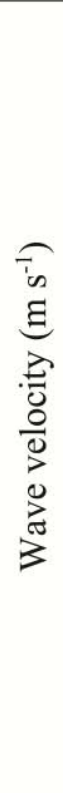 } & 500 & & & & \\
\hline & 600 & 0.85 & 0.92 & 1.02 & 0.99 \\
\hline & 700 & 0.86 & 0.86 & 1.13 & 1.08 \\
\hline & 800 & 0.83 & 1.01 & 1.05 & 1.22 \\
\hline & 900 & 1.02 & 1.10 & 1.13 & 1.10 \\
\hline & 1000 & 1.04 & 1.12 & 1.06 & \\
\hline & 1100 & 1.00 & 1.05 & 1.12 & \\
\hline & 1200 & 1.08 & 1.13 & & \\
\hline & 1300 & 1.12 & 1.12 & & \\
\hline & 1400 & 1.00 & & & \\
\hline & 1500 & 1.06 & & & \\
\hline & 1600 & 1.03 & & & \\
\hline
\end{tabular}

\begin{tabular}{|c|c|c|c|c|c|}
\hline \multirow{2}{*}{\multicolumn{2}{|c|}{$\mathrm{R}_{\mathrm{NEO}-\mathrm{dcNEO}}$}} & \multicolumn{4}{|c|}{ Gas flow $\left(\mathrm{mL} \mathrm{min}^{-1}\right)$} \\
\hline & & 60 & 70 & 80 & 90 \\
\hline & 400 & 0.83 & 0.90 & 0.95 & 1.03 \\
\hline in & 500 & 0.98 & 1.05 & 1.00 & 1.00 \\
\hline$\Xi$ & 600 & 1.01 & 1.02 & 1.09 & 1.05 \\
\hline : & 700 & 1.06 & 1.06 & 1.01 & \\
\hline$\stackrel{0}{7}$ & 800 & 1.01 & 1.04 & & \\
\hline 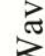 & 900 & 1.05 & & & \\
\hline & 1000 & 1.02 & & & \\
\hline
\end{tabular}

The highest resolution between NEO and dcNEO was observed for a wave velocity of $800 \mathrm{~m}$ $\mathrm{s}^{-1}$, a wave height of $40 \mathrm{~V}$ and a gas flow of $90 \mathrm{~mL} \mathrm{~min}^{-1}$ whereas the highest drift time difference between NEO and dcNEO was observed for a wave velocity of $700 \mathrm{~m} \mathrm{~s}^{-1}$, a wave height of $30 \mathrm{~V}$ and a gas flow of $80 \mathrm{~mL} \mathrm{~min}^{-1}$. 
Table S4. Drift time difference between GTX2/3 and dcGTX2/3 for different ion mobility parameters in negative ionization mode. (a) wave height of $40 \mathrm{~V}$, (b) wave height of $30 \mathrm{~V}$. The green values correspond to the most important drift time difference and red values to the lowest differences. The bolt value corresponds to the highest drift time differences.

\begin{tabular}{|c|c|c|c|c|c|}
\hline \multirow{2}{*}{\multicolumn{2}{|c|}{$\Delta_{\mathrm{GTX} 2 / 3-\mathrm{dcGTX} 2 / 3}$}} & \multicolumn{4}{|c|}{ Gas flow $\left(\mathrm{mL} \mathrm{min}^{-1}\right)$} \\
\hline & & 60 & \multirow{2}{*}{$\begin{array}{c}70 \\
0.24\end{array}$} & \multirow{2}{*}{\begin{tabular}{|c|}
80 \\
0.31
\end{tabular}} & \multirow{2}{*}{$\begin{array}{r}90 \\
0.35\end{array}$} \\
\hline \multirow{12}{*}{ 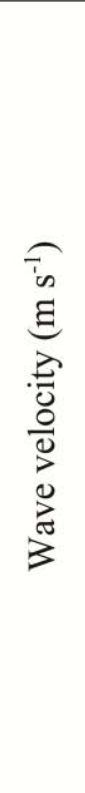 } & 500 & 0.21 & & & \\
\hline & 600 & 0.23 & 0.29 & 0.29 & 0.39 \\
\hline & 700 & 0.25 & 0.32 & 0.40 & 0.45 \\
\hline & 800 & 0.29 & 0.37 & 0.43 & 0.50 \\
\hline & 900 & 0.34 & 0.42 & 0.50 & 0.58 \\
\hline & 1000 & 0.37 & 0.46 & 0.55 & \\
\hline & 1100 & 0.41 & 0.52 & 0.62 & \\
\hline & 1200 & 0.45 & 0.56 & & \\
\hline & 1300 & 0.49 & 0.61 & & \\
\hline & 1400 & 0.55 & & & \\
\hline & 1500 & 0.57 & & & \\
\hline & 1600 & 0.61 & & & \\
\hline
\end{tabular}

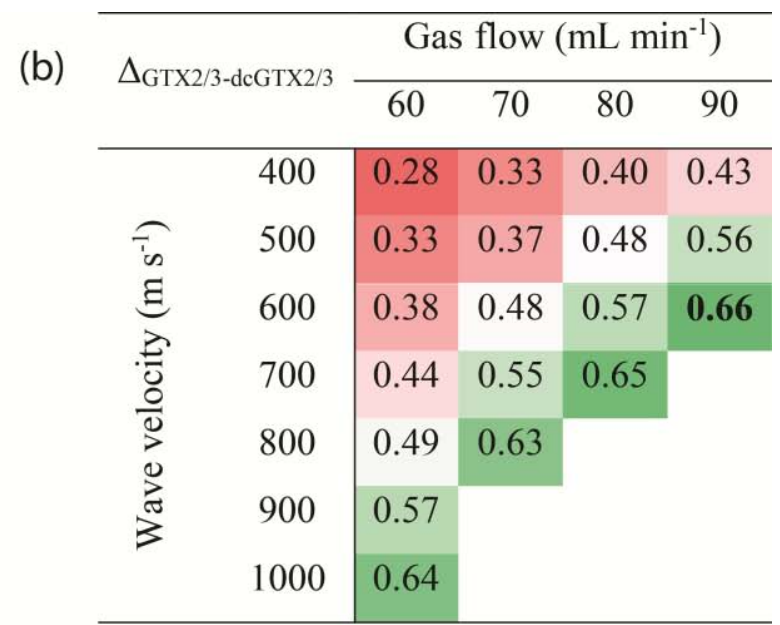


Table S5. Resolution peak to peak between GTX2/3 and dcGTX2/3 for different ion mobility parameters in negative ionization mode. (a) wave height of $40 \mathrm{~V}$, (b) wave height of $30 \mathrm{~V}$. The green values correspond to the most important drift time difference and red values to the lowest differences. The bolt value corresponds to the highest drift time differences.

\begin{tabular}{|c|c|c|c|c|c|}
\hline \multirow{2}{*}{\multicolumn{2}{|c|}{$\mathrm{R}_{\mathrm{GTX} 2 / 3-\mathrm{dcGTX} 2 / 3}$}} & \multicolumn{4}{|c|}{ Gas flow $\left(\mathrm{mL} \mathrm{min}^{-1}\right)$} \\
\hline & & 60 & 70 & 80 & 90 \\
\hline & 500 & 0.56 & 0.59 & 1.01 & 1.01 \\
\hline & 600 & 0.59 & 0.64 & 0.89 & 1.04 \\
\hline & 700 & 0.63 & 0.63 & 0.99 & 1.07 \\
\hline & 800 & 0.61 & 0.66 & 0.98 & 0.94 \\
\hline ' & 900 & 0.78 & 0.67 & 0.97 & 1.05 \\
\hline ¿ & 1000 & 0.65 & 0.66 & 0.97 & \\
\hline$\frac{0}{0}$ & 1100 & 0.64 & 0.64 & 1.02 & \\
\hline 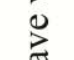 & 1200 & 0.65 & 0.62 & & \\
\hline 3 & 1300 & 0.63 & 0.76 & & \\
\hline & 1400 & 0.61 & & & \\
\hline & 1500 & 0.60 & & & \\
\hline & 1600 & 0.59 & & & \\
\hline
\end{tabular}

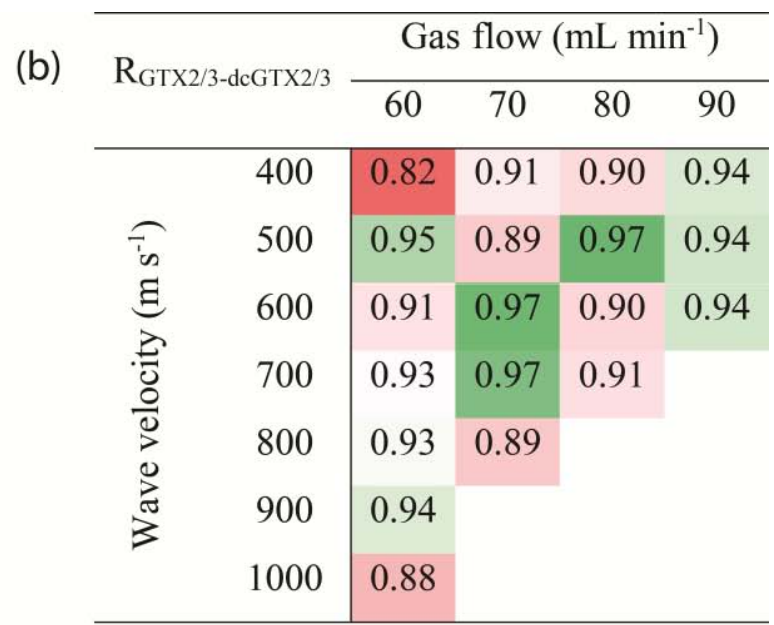

The highest resolution between GTX2/3 and dcGTX2/3 was observed for a wave velocity of $700 \mathrm{~m} \mathrm{~s}^{-1}$, a wave height of $40 \mathrm{~V}$ and a gas flow of $90 \mathrm{~mL} \mathrm{~min}^{-1}$ whereas the highest drift time difference between GTX2/3 and dcGTX2/3 was observed for a wave velocity of $600 \mathrm{~m} \mathrm{~s}^{-1}$, a wave height of $30 \mathrm{~V}$ and a gas flow of $90 \mathrm{~mL} \mathrm{~min}^{-1}$. 
Table S6. CCS reproducibility of the saxitoxin for different ion mobility conditions with wave height at $40 \mathrm{~V}$ and gas flow at $90 \mathrm{~mL} \mathrm{~min}^{-1}$

\begin{tabular}{ccccc}
\hline Wave velocity $\left(\mathrm{m} \mathrm{s}^{-1}\right)$ & $\mathrm{t}_{\mathrm{D}}(\mathrm{ms})$ & $\mathrm{t}_{\mathrm{D}}{ }^{\prime \prime}(\mathrm{ms})$ & Calibration curve $^{\mathrm{a}}$ & CCS $\left(\AA^{2}\right)$ \\
\hline 700 & 2.94 & 2.48 & $\mathrm{y}=268.96236 \mathrm{x}^{0.65787}$ & 96.7 \\
800 & 3.32 & 2.86 & $\mathrm{y}=241.49235 \mathrm{x}^{0.67114}$ & 96.7 \\
900 & 3.80 & 3.34 & $\mathrm{y}=217.09881 \mathrm{x}^{0.67552}$ & 96.9 \\
1000 & 4.16 & 3.70 & $\mathrm{y}=199.69657 \mathrm{x}^{0.68637}$ & 96.9 \\
\hline
\end{tabular}

${ }^{\mathrm{a}}$ Curves obtained using the CCS values of polyalanine in He.

Calibration using different parameters of wave height and gas flow were also performed to give similar CCS values. 
Table S7. Experimental and theoretically calculated CCS averages in $\mathrm{He}\left(\AA^{2}\right)$

\begin{tabular}{ccccc}
\hline Toxin & CCSexp & CCScalc (TM) & CCScalc (PA) & CCScalc (EHSS) \\
\hline NEO & 99.2 & 103.6 & 103.1 & 111.2 \\
dcNEO & 91.8 & 90.4 & 92.7 & 99.3 \\
STX & 97.2 & 102.3 & 101.8 & 109.3 \\
dcSTX & 89.7 & 89.8 & 91.8 & 98.0 \\
GTX1 & 116.9 & 117.7 & 120.2 & 129.8 \\
GTX4 & 114.0 & 117.6 & 120.0 & 129.8 \\
GTX2 & 115.2 & 117.2 & 119.6 & 128.8 \\
GTX3 & 113.8 & 116.8 & 119.5 & 128.5 \\
dcGTX2 & 106.4 & 104.4 & 109.1 & 116.9 \\
dcGTX3 & 107.0 & 104.5 & 110.0 & 117.5 \\
GTX5 & 111.7 & 111.3 & 115.5 & 124.3 \\
\hline
\end{tabular}

Table S8. Experimental and theoretically calculated CCS averages in $\mathrm{N}_{2}\left(\AA^{2}\right)$

\begin{tabular}{ccccc}
\hline Toxin & CCSexp & CCScalc (TM) & CCScalc (PA) & CCScalc (EHSS) \\
\hline NEO & 163.9 & 172.4 & 103.1 & 111.3 \\
dcNEO & 154.5 & 153.3 & 92.7 & 99.4 \\
STX & 161.3 & 169.7 & 101.8 & 109.4 \\
dcSTX & 151.6 & 152.9 & 91.8 & 98.1 \\
GTX1 & 183.1 & 189.9 & 120.2 & 130.0 \\
GTX4 & 180.3 & 190.3 & 120.0 & 129.9 \\
GTX2 & 181.4 & 189.8 & 119.6 & 128.9 \\
GTX3 & 179.9 & 189.5 & 119.5 & 128.6 \\
dcGTX2 & 171.2 & 172.1 & 109.2 & 117.1 \\
dcGTX3 & 172.1 & 172.3 & 110.0 & 117.7 \\
GTX5 & 177.4 & 180.0 & 115.5 & 124.5 \\
\hline
\end{tabular}




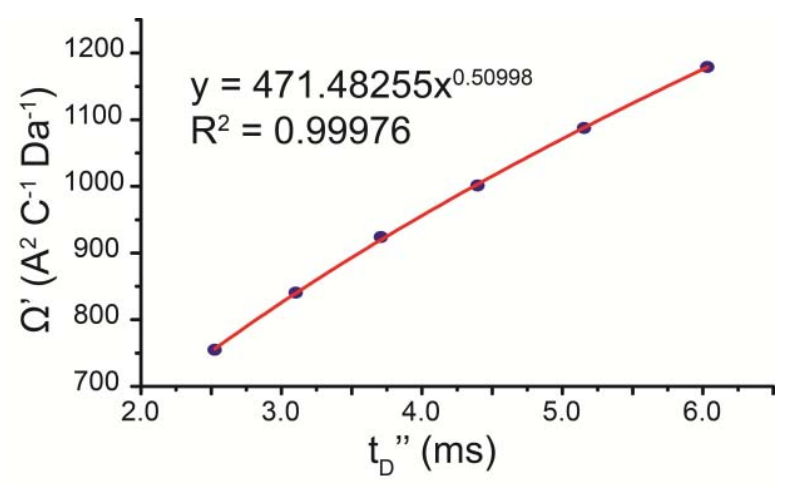

Figure S1. TWIM slope calibration using $\mathrm{N}_{2}$ polyalanine values (wave velocity of $800 \mathrm{~m} \mathrm{~s}^{-1}$, wave height of $40 \mathrm{~V}$ and gas flow of $90 \mathrm{~mL} \mathrm{~min}^{-1}$ )

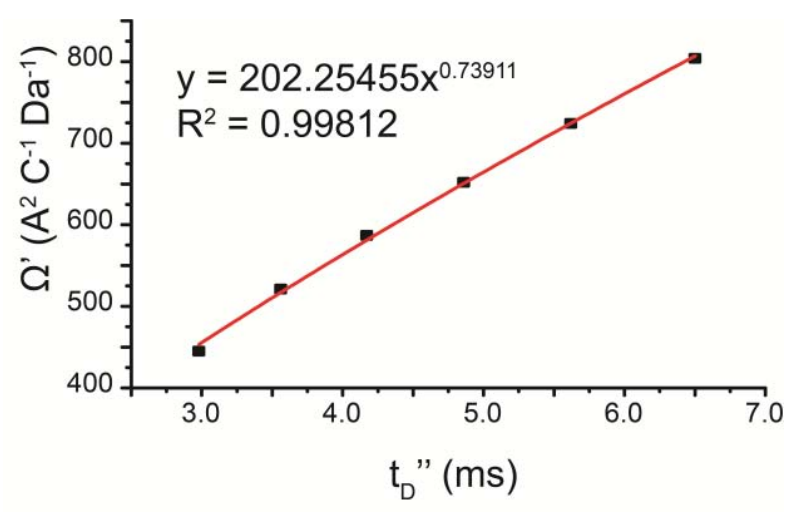

Figure S2. TWIM slope calibration using He polyalanine values (wave velocity of $800 \mathrm{~m} \mathrm{~s}^{-1}$, wave height of $40 \mathrm{~V}$ and gas flow of $90 \mathrm{~mL} \mathrm{~min}^{-1}$ )

$$
\begin{gathered}
\Omega^{\prime}=\frac{\Omega}{z} \sqrt{\mu} \\
t_{D}^{\prime \prime}=t_{D}-\frac{c}{1000} \sqrt{\frac{m}{z}}-t_{\text {transfer }}
\end{gathered}
$$

Where $\Omega$ is the CCS value of polyalanine in He or $\mathrm{N}_{2}$, c is a constant which depend on the instrument, and $t_{\text {transfer }}$ is the time spend by the ion in the transfer cell. ${ }^{[2]}$ 

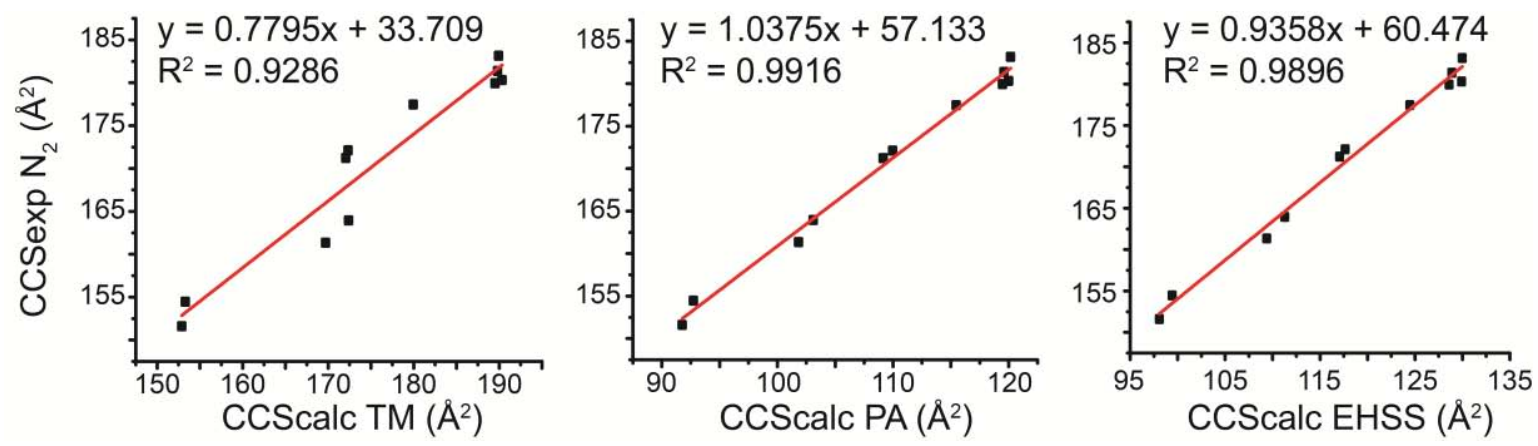

Figure S3. $\mathrm{CCS}_{\exp }=\mathrm{f}\left(\mathrm{CCS}_{\text {calc }}\right)$. Correlation between calculated and experimental CCS values obtained with MOBCAL in $\mathrm{N}_{2}$ optimised conditions. The theoretical CCS average values are calculated from values of polyalanine in $\mathrm{N}_{2}$ for calibration.

[1] V. Domalain, M. Hubert-Roux, C.M. Lange, J. Baudoux, J. Rouden, C. Afonso. Use of transition metals to improve the diastereomers differentiation by ion mobility and mass spectrometry. J Mass Spectrom 2014, 49, 423.

[2] B.T. Ruotolo, J.L.P. Benesch, A.M. Sandercock, S.-J. Hyung, C.V. Robinson. Ion mobility-mass spectrometry analysis of large protein complexes. Nat. Protocols 2008, 3, 1139. 